\title{
IATROGENIC CUSHING'S SYNDROME DUE TO MISUSE OF TOPICAL CORTICOSTEROIDS: A CASE REPORT
}

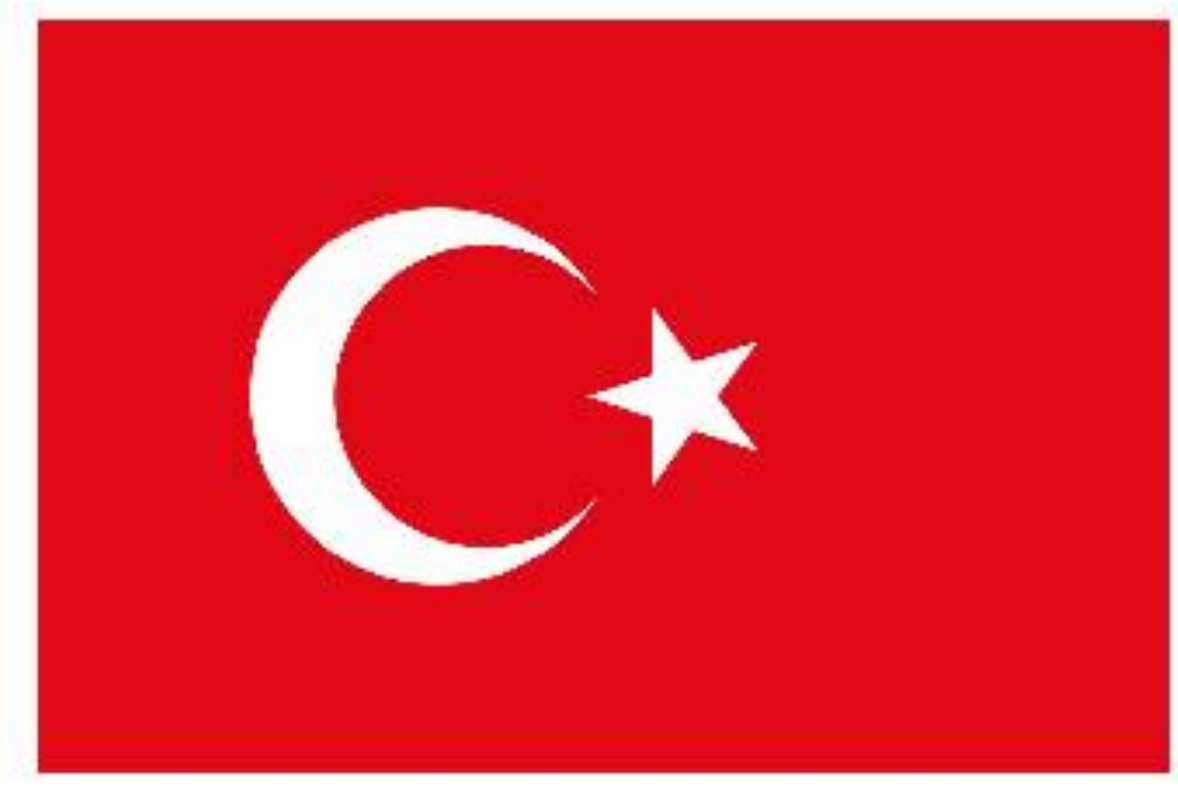

ACAR EA ${ }^{1}$, DAVARCI SE ${ }^{1}$, ERDEM N$^{1}$, ŞENOL E2, HEKIMSOY $Z^{2}$

Celal Bayar University Medical Faculty, ${ }^{1}$ Department of Internal Medicine, ${ }^{2}$ Division of Endocrinology and Metabolism, Manisa, TURKEY

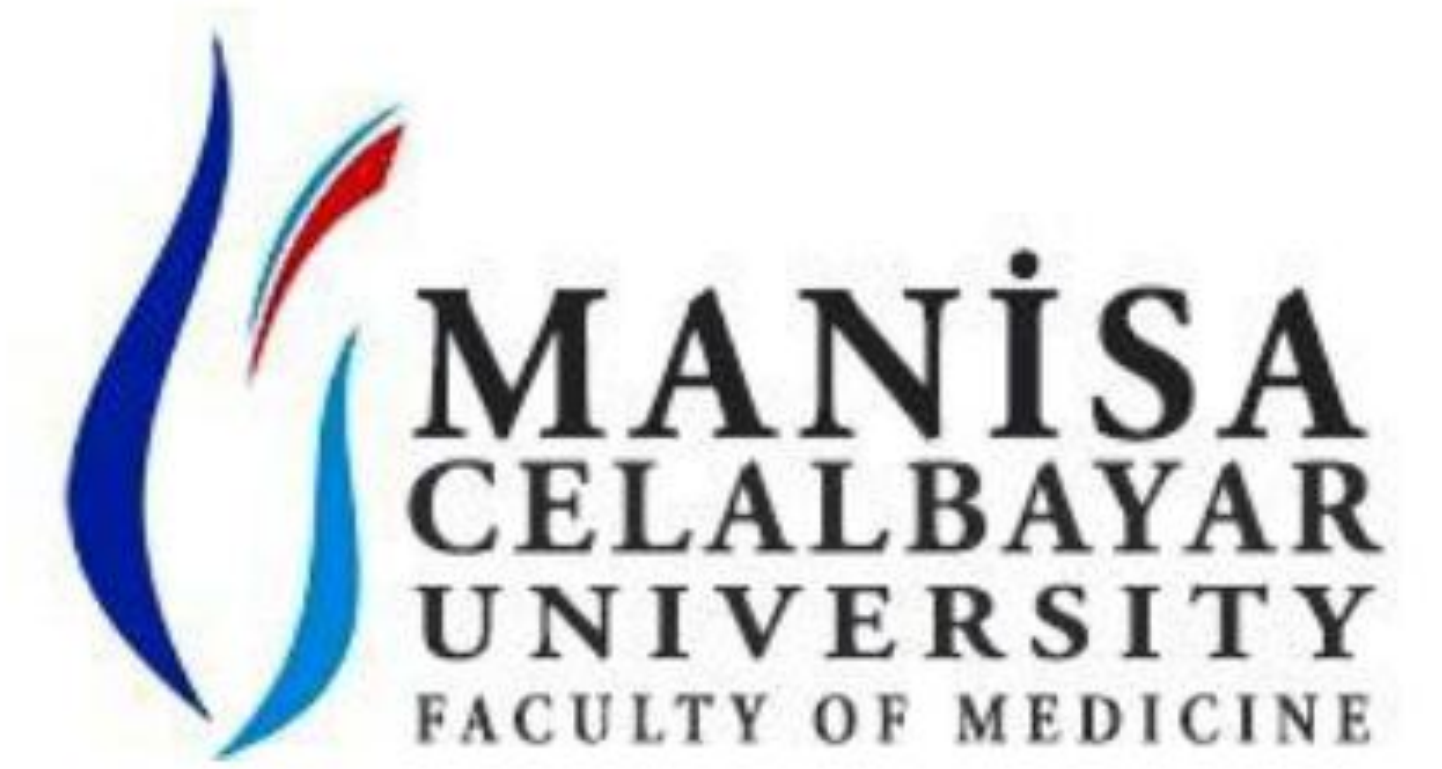

\section{INTRODUCTION}

Because of their anti-inflammatory effect, topical corticosteroids are widely used in dermatological diseases. Topical use is typically safe, but serious adverse effects induced by systemic absorption are occasionally reported. We report a patient who developed Cushing's syndrome due to long-term misuse of topical bethametasone and clobetasol.

\section{CASE REPORT}

A 24-year-old man presented with rapid weight gain and purple strias in multiple areas. He had moon face, supraclavicular fat deposition and purple strias bilaterally on the medial aspects of his arms, thighs and abdomen (Figure 1-2). We diagnosed Cushing's syndrome clinically, but his serum ACTH and cortisol levels were extremely low (Table 1). When we questioned him about using corticosteroids, he stated that he didn't use any medications.

We performed an ACTH stimulating test but he had no cortisol response (Table 1 ). We interrogated him again about medication use and learned that he had been using a steroid-containing ointment for two years due to itching in his groin region. We asked him to stop using the ointment and within 3 months, his signs of Cushing's syndrome abated.

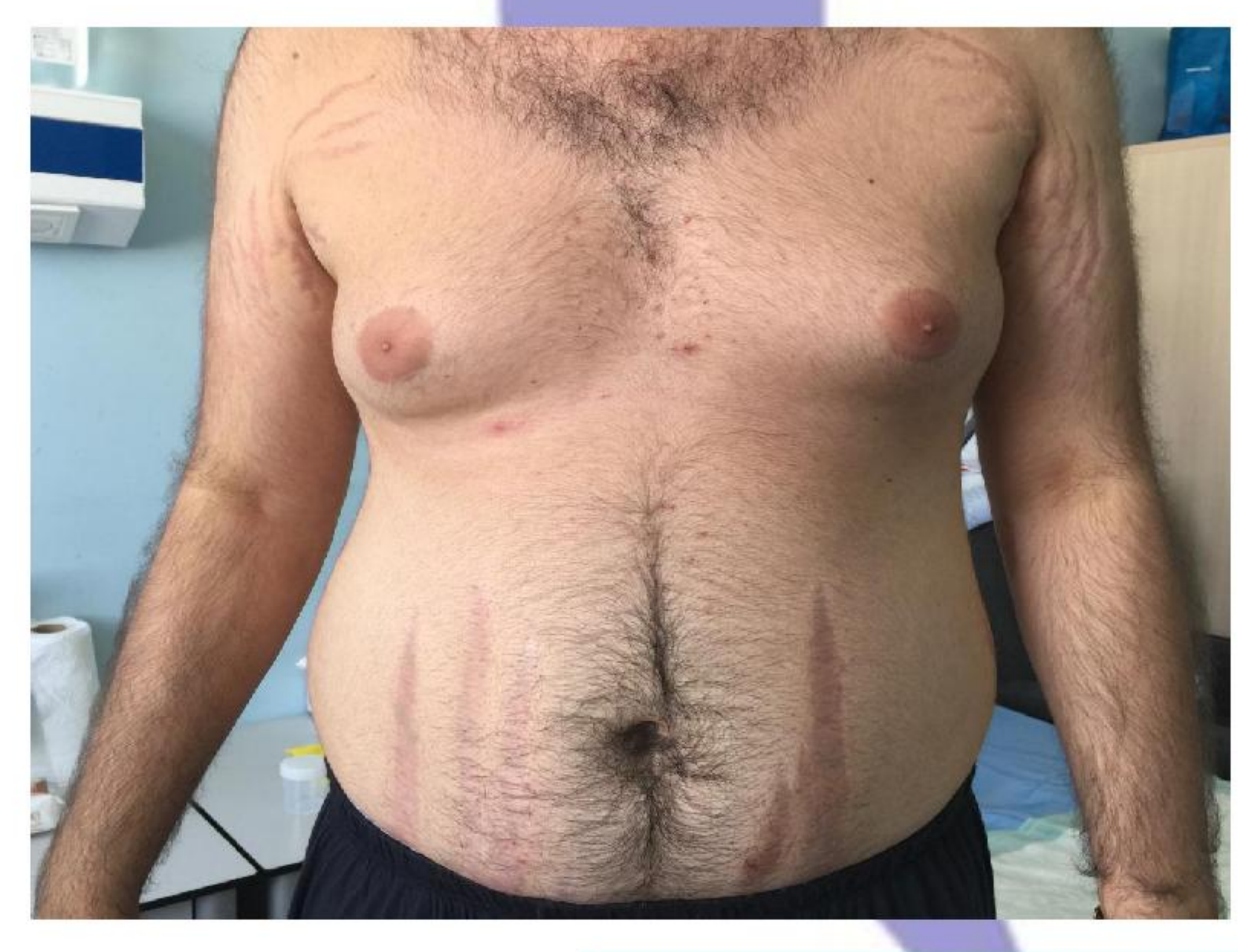

\section{DISCUSSION}

Because of their anti-inflammatory and anti-proliferative effects, topical corticosteroids have been used succesfully to treat dermatological diseases for a long while. Although absorption of topical corticosteroids is low, long-term application of these agents at high doses can increase the probability of systemic adverse events. As use of superpotent agents has increased, reports of local and systemic side effects have also increased.

The risk for developing systemic side effects depends on the agent's potency, the length of treatment, application frequency, epithelial integrity, extensiveness of applied area, and use of concomitant therapies.

The most common etiology of Cushing's syndrome is iatrogenic. The use of topical agents should always be queried when taking a medication history in order to discover any sources of exogenous steroids so that appropriate treatment may be started.

Figure 1-2. Cushingoid features of the patient

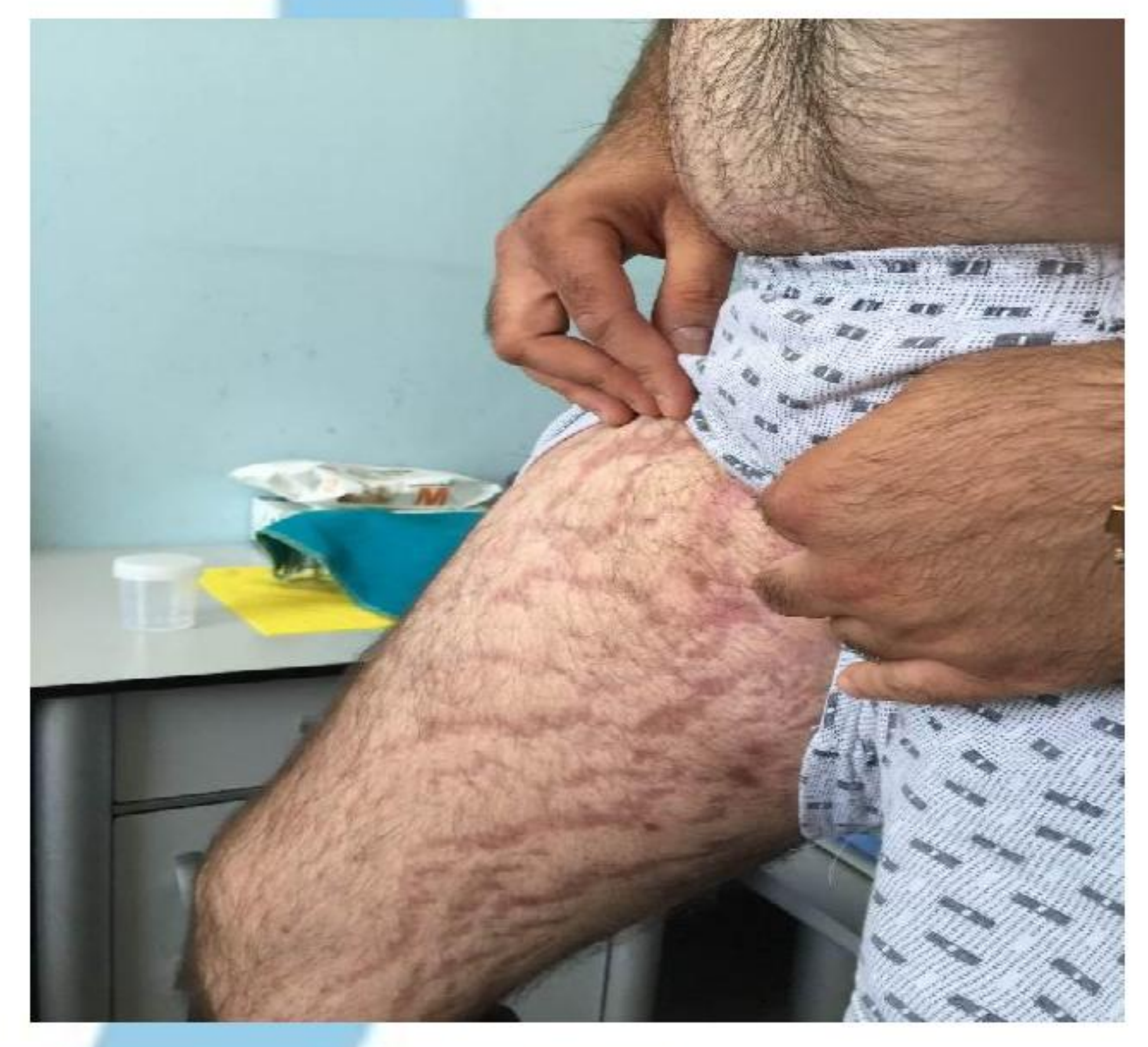

Figure 1-2. Cushingoid features of the patient

\begin{tabular}{|l|l|l|l|}
\hline & At presentation & ACTH stimulation test & $\begin{array}{c}\text { After cessation of topical } \\
\text { steroid medication }\end{array}$ \\
\hline $\begin{array}{l}\text { Cortisol } \\
(3.04-22.6 \mu \mathrm{g} / \mathrm{dl})\end{array}$ & $<0.5$ & After 2 hours: 4.77 & 7.07 \\
\hline ACTH & $<5$ & After 4 hours: 4.22 & 19.8 \\
\hline$(0-46 \mathrm{pg} / \mathrm{ml})$ & - & & \\
\hline
\end{tabular}

Table 1. Serum ACTH and cortisol levels of the patient

\section{Medical Faculty of Celal Bayar University}

